\title{
PROFESSORES NÔMADES:
}

\section{(RE)CONSTRUINDO TÁTICAS PEDAGÓGICAS NO CIBERESPAÇO}

\author{
NOMADIC TEACHERS:
}

(RE)BUILDING PEDAGOGICAL TACTICS IN CYBER SPACE

\section{PROFESORES NÓMADAS: \\ (RE)CONSTRUYENDO TÁCTICAS PEDAGÓGICAS EN EL CIBERESPACIO}

\author{
Emerson dos Santos Lima ${ }^{1}$ \\ Rozevania Valadares de Meneses César ${ }^{2}$
}

Submetido em: 15/01/2020 - Aceito em: 06/06/2020 - Publicado em: 18/08/2020.

\begin{abstract}
${ }^{1}$ Mestre em Educação pela Universidade Tiradentes (2016) e Membro do Grupo de Pesquisa Educação, Tecnologia e Contemporaneidade (GPETEC). Possui graduação em Letras/Português-Espanhol pela Universidade Tiradentes (2009), Pós-graduação Lato Sensu em Língua Espanhola pela Faculdade Pio X (2011), e em Docência e Tutoria em Educação a Distância pela Universidade Tiradentes (2012). Tem experiência no ensino superior, onde atuou como Docente Titular das Faculdades Integradas de Sergipe (FISE), ministrando disciplinas nos Cursos de Pedagogia, Ciências Biológicas, Administração, Ciências Contábeis e Letras. Nas FISE também foi membro do Núcleo Docente Estruturante (NDE) e do Colegiado do Curso de Letras. Na Universidade Tiradentes, atuou como Professor Tutor, na modalidade EAD, passando pelos Cursos de Letras Português Espanhol e Pedagogia. Ainda na EAD, ministra disciplinas no Curso de Pedagogia da Faculdade de Ensino Regional Alternativa (FERA) e em Especializações Lato Sensu da mesma Instituição. Foi Professor Conteudista de disciplinas dos Cursos Técnicos Subsequentes, na modalidade EAD, do Instituto Federal de Sergipe; onde atuou também como Coordenador de Polo do Campus Aracaju. Ainda no IFS, foi Professor Substituto de Língua Portuguesa, nas turmas do ensino médio integrado. Ainda na educação básica, tem experiência com Leitura, Produção, Compreensão e Interpretação de Textos nas Línguas Portuguesa e Espanhola; com Educação de Jovens e Adultos. Também possui experiência com a educação inclusiva e com inclusão digital.
\end{abstract}

${ }^{2}$ Mestra em Educação pela Universidade Tiradentes (UNIT). Possui pós-graduação em Educação, Diversidade e Inclusão Social pela Faculdade Dom Bosco (UCDB),Didática do Ensino Superior pela Faculdade Pio Décimo (PIO X), Direitos Infanto-Juvenis no Ambiente Escolar (A Escola que protege) pela Universidade Federal de Sergipe (UFS) e História e Cultura Afro ? Brasileira pela Faculdade Venda Nova do Imigrante (FAVENI).Possui graduação em Pedagogia pela Faculdade Pio Décimo (PIO X), Graduação em História pela Universidade Federal de Sergipe (UFS). Atua como professora das Faculdades Integradas de Sergipe (FISE) ministrando disciplinas na modalidade presencial e Ead. Atualmente exerce a função de professora do Ensino Fundamental II, Educação de Jovens e Adultos e Nível Médio pela Secretaria de Estado da Educação (SEED), Professora do Ensino Fundamental II, pela Secretaria Municipal de Educação de Itapicuru (SMEI). Atuou como Tutora na Universidade Tiradentes (UNIT). Atuou como coordenadora da Escola Ativa. Pesquisadora 


\section{RESUMO}

O presente texto tem como objetivo compreender o modelo de trabalho desenvolvido por nômades digitais que têm se ampliado no mercado online e como a educação adentrou também nesse universo. Para alcançar esse objetivo, a metodologia utilizada consiste na netnografia, defendida por Fragoso, Recuero e Amaral (2016), que possibilitou mergulhar no ambiente online. Somando-se a esse referencial, utilizou-se os conceitos de "táticas" e "estratégias", de Certeau (1998), que permitiu compreender quais são os modos de trabalho utilizados pelos nômades digitais e ainda operou-se com o conceito de cultura da convergência, de Jenkins (2009), para perceber como a educação ocorre no ciberespaço. Assim, pôde-se verificar que os professores nômades fazem a convergência entre as mídias e não transmidiação dos conteúdos, e que, além disso, suas práticas seguem a mesma linha dos professores que atuam na sala de aula convencional, ou seja, tem relação direta com ensino e aprendizagem, porém se apropriam das oportunidades proporcionadas pelo universo online, para vender seus cursos, utilizando métodos e táticas de trabalhos criativos e colaborativos.

PALAVRAS-CHAVE: Mundo Digital. Professores Nômades. Táticas.

\section{ABSTRACT}

The present text aims to comprehend the work model developed by digital nomads that have expanded in the online market and how education has also entered in this universe. To achieve this goal, the methodology used consists of netnography, defended by Fragoso, Recuero and Amaral (2016), which made it possible to dive into the online environment. In addition to this referential, Certeau's (1998) concepts of "tactics" and "strategies" was used, which allowed us to comprehend which are the working methods used by digital nomads and also operated with the concept of culture convergence, of Jenkins (2009), to perceive how education takes place in cyberspace. Thus, it was possible to verify that the nomadic teachers make the convergence between the media and not the transmedia of contents, and that, in addition, their practices follow the same line as the teachers who work in the conventional classroom, that is, they have a direct relationship with teaching and learning, however they take advantage of the opportunities provided by the online universe, to sell their courses, using creative and collaborative working methods and tactics.

KEYWORDS: Digital World. Nomadic Teachers. Tactics.

\section{RESUMEN}

El presente texto tiene como objetivo comprender el modelo de trabajo desarrollado por nómadas digitales que crece en el mercado online y cómo la educación ha adentrado también en ese universo. Para alcanzar este objetivo, la metodología utilizada consiste en la netnografía, defendida por Fragoso, Recuero y Amaral (2016), que posibilitó bucear en el ambiente online. Somándose a este referencial, se utilizó los conceptos de "táctica" y "estrategias", de Certeau (1998), que permitió comprender cuales son los modos de trabajo utilizados por los nómadas digitales y todavía operó con el concepto de cultura da convergencia, de Jenkins (2009), para percibir cómo la educación ocurre en el espacio virtual. Así, se pudo verificar que los profesores nómadas hacen la convergencia entre las medios de comunicación, y no transmidiación de los contenidos, y que, además de eso, sus prácticas siguen la misma linea de los profesores que actúan en el salón de clases convencional, o sea, tiene relación directa con la enseñanza y el aprendizaje, pero se apropían de las oportunidades proporcionadas por el universo online, para vender sus cursos, utilizando métodos y tácticas de trabajos creativos y colaborativos.

PALABRAS CLAVE: Mundo Digital. Profesores Nómadas. Tácticas.

vinculada ao Projeto de Pesquisa e extensão Integrado - Formação, Métodos e Práticas Pedagógicas, 2017. Realiza pesquisa em Educação, com ênfase para o Nomadismo Digital e a educação. Possui experiências com ênfase na Educação de Jovens e Adultos. 


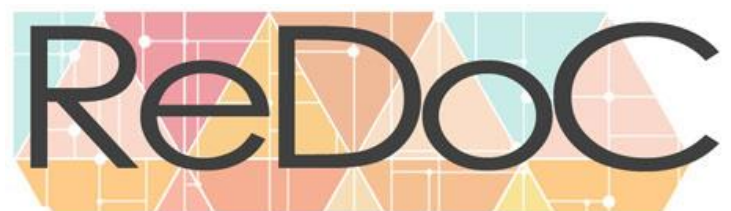

Revista Docência e Cibercultura

\section{INTRODUÇÃO}

Os Nômades foram povos datados do período paleolítico, que se deslocavam constantemente em busca de alimento e água para sobreviver, quando estes itens ficavam escassos naquela região. Até hoje ainda há pessoas que não têm moradia fixa e levam um estilo de vida andarilho, além disso, esse nomadismo não se limita apenas a mudança de endereço, tampouco a busca por alimento ou água.

Com o advento da tecnologia, surge também um movimento denominado "nômades digitais", que também buscam por sobrevivência, sendo que, em muitos casos, para o mercado de trabalho; e utilizam "táticas" para (re)inventar formas de trabalhar, isso porque, na sociedade atual, informatizada e midiatizada, os sujeitos interagem em qualquer hora e lugar. Para tanto, basta ter à sua disposição um dispositivo móvel conectado à internet, e, assim, a comunicação que antes ocorria de forma verbal ou escrita, agora, passa a ser instantânea e em tempo real.

Aprofundando o tratamento da questão, Lima, Mercado e Versuti (2017, p. 4) consideram que "Essas linguagens surgem com o desenvolvimento das tecnologias digitais da informação e comunicação (TDIC), a partir do desenvolvimento social e das necessidades que surgem por meio desse desenvolvimento". No âmbito educacional, por exemplo, tais linguagens têm se ampliado, visto que os professores também se apropriam de espaços virtuais para compartilhar experiências, (re)produzir conteúdos para utilizar na sua prática pedagógica, ou ainda para ministrar cursos de curta e longa duração, apropriando-se de tais espaços.

Ainda de acordo com Lima, Macedo e Versuti (2017), esses cursos são disponibilizados em diferentes plataformas, que dão suporte para a comunicação dos sujeitos imersos na cultura digital, tais como: Whatsapp, Instagram, Facebook, Google, Youtube e o Twitter, que oferecem distintas linguagens para a comunicação entre seus usuários. Assim, a problemática central circunscreve em torno do entendimento que existem experiências nômades relacionadas à educação, portanto, indagamos: Quais são os métodos e as táticas utilizados pelos professores que se intitulam como nômades para fazer educação no mundo digital? E como a educação adentrou também nesse universo?

Diante do exposto, vale destacar que este texto objetiva, portanto, compreender o modelo de trabalho desenvolvido por nômades digitais que têm se ampliado no mercado online e como a educação adentrou também nesse universo. 


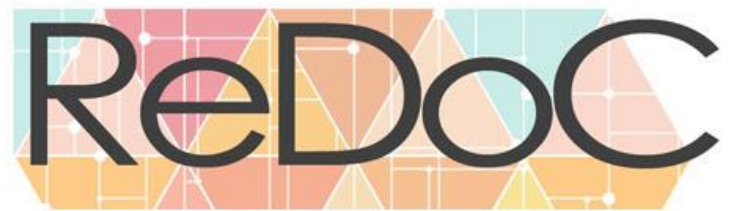

Revista Docência e Cibercultura

Para alcançar este objetivo, operou-se com a netnografia ${ }^{3}$, que, para Fragoso, Recuero e Amaral (2016, p. 198), trata-se de um “[...] neologismo criado no final dos anos $90^{4}$ (net + etnografia) para demarcar as adaptações do método etnográfico em relação tanto à coleta e análise de dados, quanto à ética de pesquisa". Assim, a netnografia é uma abordagem de pesquisa (re)formulada a partir da etnografia para estudar grupos ou comunidades em ambientes virtuais.

Ainda neste artigo, são descritas algumas experiências de professores nômades, mediante uma pesquisa bibliográfica. Também foram visitadas as páginas dos blogs, para compreender como ocorre o processo de transmidiação dos conteúdos entre as mídias utilizadas pelos professores nômades, para criar os recursos didáticos, e ministrar as aulas e/ou os cursos nas suas interfaces de trabalho.

Como referencial teórico, lança-se mão dos conceitos de táticas e estratégias de Certeau (1998), que permitiu compreender quais são os modos de trabalho utilizados pelos nômades digitais. Utilizou-se também o conceito de cultura da convergência, de Jenkins (2009), ao considerar as plataformas complementares, às quais os nômades recorrem para postar seus materiais, e a narrativa transmídia para pensá-la como potencialidade na arte de fazer do campo educacional.

Vale ressaltar que as discussões deste artigo descendem da Dissertação de Mestrado em Educação, intitulada "Nomadismo digital e educação: limites e potencialidades das táticas de transmidiação".

\section{TRANSMIDIAÇÃO E TÁTICAS PEDAGÓgICAS NO MUNDO DIGITAL}

Antes de adentrar à temática abordada nesta seção, é importante esclarecer que a escolha dos professores, sujeitos da pesquisa, deu-se em razão dos autores deste artigo terem sido protagonistas de cursos de curta e longa duração na modalidade de Educação a Distância, além de atuar em sala de aula e, por vezes, recorrer aos blogs para coletar ideias concernentes a atividades dos professores nômades.

\footnotetext{
${ }^{3} \mathrm{O}$ método netnográfico teve início nos anos 90, principalmente, no âmbito da pesquisa de marketing e de consumo. Trata-se, portanto, de uma área interdisciplinar que tem se destacado por agregar pontos de vista de outras áreas, como a antropologia, a sociologia e os estudos culturais (KOZINETS, 2014).

${ }^{4}$ Período correspondente à década de 1990.
} 
Destarte, é importante apresentar os sujeitos da pesquisa, ou seja, esses professores nômades. São eles: Lívia Alencar, Rodolfo Neves, Daniel Pereira, Paulo Jubilut e Mairo Vergara, os quais desenvolvem suas atividades em interfaces.

A fim de clarear as razões pelas quais os professores informados acima foram escolhidos para participar desta investigação, é imperioso apresentá-los, trazendo informações acerca de cada um deles, bem como da sua atuação no campo da educação. Sendo assim, a professora Lívia Alencar é graduada em Letras/Inglês, natural da cidade de São Carlos, município de São Paulo. Desenvolveu um método de contação de histórias, criou um curso Básico On-line de Técnicas de Contação de Histórias e é empreendedora digital.

Rodolfo Neves é sociólogo, formado pela Universidade Estadual Paulista (UNESP), leciona a disciplina História, há 25 anos, em cursos preparatórios para vestibulares, além disso é sócio e fundador do site História On-line. Já o professor Daniel Pereira é formado em Ciências Sociais e leciona Filosofia e Atualidades, em cursos preparatórios para vestibulares, e também é sócio e fundador do site História On-line.

Paulo Jubilut possui licenciatura e bacharelado em Ciências Biológicas, pela Universidade Federal de Santa Catarina (UFSC), e, em 2013, criou sua empresa, a Biologia Total, que vende pacotes de videoaulas sobre todas as áreas da biologia. Há conteúdo para ensino médio, específico para preparação de vestibulares e Exame Nacional do Ensino Médio (Enem), além de ensino superior.

Por último, porém, não menos importante, Mairo Vergara, que, por sua vez, é professor de Inglês, graduado em Letras, pela Universidade Estadual de Londrina (UEL), com habilitação em Língua Portuguesa, Língua Inglesa e respectivas literaturas. Desenvolveu um método de inglês, criou um curso on-line, que leva seu nome, e já atendeu cerca de 40 mil alunos, desde que começou, em 2014. É também empreendedor digital, criador do site e curso de inglês "Mairo Vergara", YouTube videocreator, Gary Vee fan. É um entusiasta pelo ensino de idiomas estrangeiros, que propõe o uso de métodos e técnicas completamente diferentes dos tradicionais, buscando sempre as formas de aprendizado mais efetivas possíveis para os alunos.

A partir dos trabalhos apresentados pelos docentes citados, foram analisados os recursos eminentemente didáticos, tais como: games, mensagens, objetos virtuais de aprendizagem, $e$ books, videoaulas, avaliações e simulados; os quais proporcionam algum tipo de 


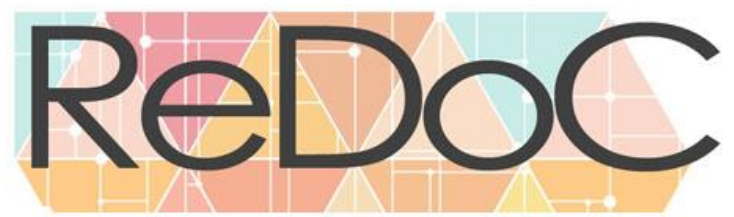

Revista Docência e Cibercultura

"ensinagem"5. Os blogs pesquisados permitiram observar e explorar também textos, áudios, vídeos, e imagens, além das propostas dos cursos que são ofertados. De acordo Renó, Versuti e Renó (2012, p. 55),

Os blogs nasceram nos finais dos anos 1990, mas não eram populares, e tampouco eram como são hoje. O primeiro blog 'popular', Scripting News, tinha uma interface simples, nada comparado com os atuais, mas tinha um conceito que até hoje faz a diferença entre os outros meios de comunicação digital, a possibilidade de comentário.

Ressalta-se ainda que, embora os blogs sejam comuns nos dias atuais, nem sempre foi assim. No caso da educação, por exemplo, os professores tinham que elaborar e desenvolver suas aulas a partir de um livro didático e do quadro de giz, o que tornava as aulas enfadonhas, mas era o que tinham disponível naquele momento.

Porém, na sociedade atual, faz-se necessário reinventar "novas" práticas e artes de fazer muitas vezes improvisadas. Certeau (2009) nomeou tais ações como "bricolagem" ou ainda "[...] mil maneiras de fazer com" (CERTEAU, 2009, p. 86). Assim, nos dias atuais, tendo em vista a variedade de possibilidades disponível na era digital, os professores também encontram mecanismos para desenvolver suas atividades de maneira mais atrativa e menos tediosa a partir dos dispositivos tecnológicos.

Para tanto, utilizam-se da criatividade para sobressair no mercado de trabalho, principalmente aqueles que, sem vínculo formal, dependem única e exclusivamente de sua criatividade para subsistir, tornando-se potencialmente autônomos. Diante desta necessidade, as práticas pedagógicas estão ancoradas em ideias de teóricos que ajudam o professor a encontrar mecanismos que facilitem o processo de ensinagem.

Por outro lado, nem sempre é possível fazer esta ponte, uma vez que o cotidiano das escolas possui realidades dissociadas do que é apresentado na teoria, e, assim, o professor é levado a criar meios para que a aprendizagem aconteça, valendo-se de inventividade e adequando-se ao público-alvo (alunos) em que a escola está inserida.

\footnotetext{
${ }^{5}$ A expressão "ensinagem" foi inicialmente explicitada no texto de Lea das Gracas Camargos Anastasiou, que é resultante da pesquisa de doutorado intitulada "Metodologia de ensino superior: da prática docente a uma possível teoria pedagógica", de 1998, O termo é adotado para significar uma situação de ensino da qual necessariamente decorra a aprendizagem, sendo a parceria entre professor e alunos a condição fundamental para o enfrentamento do conhecimento, necessário a formação do aluno durante o cursar da graduação.
} 


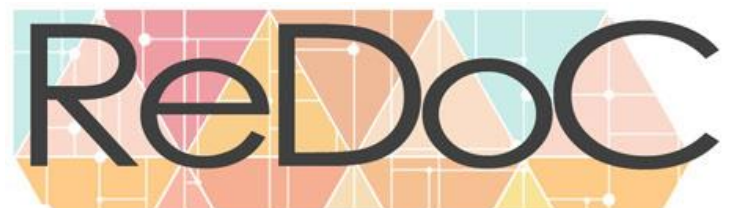

\section{Revista Docência e Cibercultura}

Assim, o modo de "fazer" do professor também é alterado, uma vez que passa a utilizar-se de recursos pedagógicos variados, com o intuito de facilitar a transmissão e absorção dos conteúdos curriculares, o que inclui o universo digital.

Sob essa ótica, recurso pedagógico é todo material utilizado pelo professor em sala de aula com a finalidade de facilitar o processo de ensinagem. Outros recursos que facilitam o já citado processo são os audiovisuais - filmes, câmeras de filmar, rádio, televisão e vídeo, como também os recursos advindos da tecnologia, as multimídias, tais como: computador, quadro interativo, internet, Prezi ${ }^{6}, \mathrm{Kahoot}^{7}$ e Voki ${ }^{8}$. Isso posto, os recursos didáticos têm, como finalidade, provocar, no aluno, fascínio, concentração e fixação do conteúdo, além de favorecer o entendimento, ajudando na concretização e abstração do conhecimento.

Cabe notificar que a função dos recursos didáticos, dentre outras razões, pauta-se na comunicação, compreensão e estruturação da aprendizagem, com a finalidade de provocar no aluno a aquisição de conhecimentos significativos, despertando-lhe a curiosidade de querer buscar mais informação sobre o que lhe foi apresentado.

Ressalta-se, entretanto, que ainda existem escolas que não dispõem de materiais didáticos suficientes para que as atividades sejam desenvolvidas a contento, sendo, muitas vezes, necessário que o professor improvise a partir do que há disponível no momento.

Tais ações podem ser entendidas, à luz de Certeau (2009), como “improviso", pois, ao analisar estratégias e táticas, como conceitos, uma vez que denominam ações de agentes distintos, ele conclui que as estratégias são ações projetadas por quem tem domínio sobre o espaço, ao passo que as táticas não possuem um lugar próprio. Quando este escreveu que, na

\footnotetext{
${ }^{6}$ Um programa para a construção de apresentações, o qual permite que o usuário aproveite as vantagens da computação em nuvem e do zoom para elaborar mostras sequenciais e não lineares de quadros com textos, fotos, tabelas, gráficos e o que mais precisar na hora de sua exposição oral. Disponível em: http://www.smartal k.com.br/ja-ouviu-falar-prezi-conheca-uma-ferramenta-para-inovar-em-suas-apresentacoes/. Acesso em: 14 Mar. 2020.

${ }^{7}$ Um sistema de questionários online criado na Noruega e que está ganhando cada vez mais espaço nas escolas dos Estados Unidos da América. Funciona como um programa de televisão, misturado com um jogo de videogame. Colocando-se no papel de apresentadores, os professores fazem uma pergunta de múltipla escolha sobre plantas ou gramática de língua inglesa. Utilizando a plataforma do Kahoot, eles projetam uma pergunta de cada vez em uma tela na frente dos alunos. Disponível em: http://www.gazetadopovo.com.br/educacao/apli cativo-transforma-ensino-em-sala-de-aula-em-game-de-conhecimento-5o6byv02zkjpjq6vp7q1khnh3. Acesso em: 14 Mar. 2020.

${ }^{8}$ É um software que nos permite criar um avatar personalizado com recurso de voz. Possibilitando inserir em páginas da internet, apresentar em blogs, enviar por e-mail e criar coleções de animações, sendo totalmente configurado. Disponível em: https://sites.google.com/site/topsferramentas/2-ferramentas-tecnologicas/2-3-ferr amenta-voki. Acesso em: 14 Mar. 2020.
} 


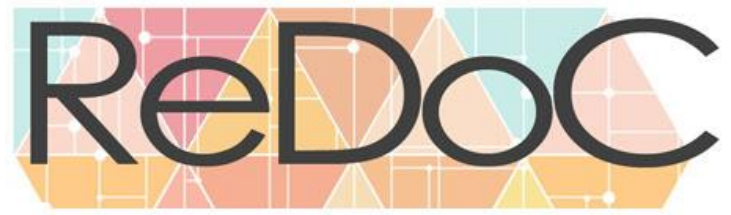

\section{Revista Docência e Cibercultura}

rotina diária, os sujeitos se deparam com situações obscuras e são obrigados a enfrentá-las para sobreviver, ele assim concluiu:

[...] o cálculo (ou manipulação) das relações de forças que se torna possível a partir do momento em que um sujeito de querer e poder (uma empresa, um exército, uma cidade, uma instituição científica) pode ser isolada. A estratégia postula um lugar suscetível de ser circunscrito como algo próprio a ser a base de onde se podem gerir as relações com uma exterioridade de alvos ou ameaças (os clientes ou os concorrentes, os inimigos, o campo em torno da cidade, os objetivos e objetos da pesquisa etc.). Como na administração de empresas, toda racionalização "estratégica" procura em primeiro lugar distinguir de um "ambiente" um "próprio", isto é, o lugar do poder e do querer próprios. Gesto cartesiano, quem sabe: circunscrever um próprio num mundo enfeitiçado pelos poderes invisíveis do Outro. Gesto da modernidade científica, política ou militar (CERTEAU, 2009, p. 93).

Ainda consoante o pensamento de Certeau (2009), as estratégias estão ligadas à autoridade, ao poder supremo que busca dominar o fraco por meio da coercitividade - campo de atuação ou espaço onde desempenham suas funções, caracterizando-se, portanto, em uma ação dos fortes sobre os fracos.

Tal premissa permite concluir que fatores como crise no trabalho tradicional, novos formatos de "ensinagem", flexibilidade e mobilidade propiciadas pelo aceleramento das tecnologias digitais móveis podem ser caracterizados como válvula de escape para fugir das estratégias e buscar uma forma de trabalho mais criativa, valendo-se das "táticas", criando, assim, atividades que podem ser desenvolvidas remotamente, porém com a mesma responsabilidade dos tipos de atividades do mercado formal. Isso porque as táticas devem ser tão eficientes quanto as estratégias.

$\mathrm{Na}$ área educacional, o professor trabalha sob orientação de estrategistas, a exemplo dos agentes que compõem o Ministério de Educação (MEC), órgão que gerencia as políticas de ensino e também é responsável por desenvolver e administrar as esferas da educação no Brasil, abrangendo todos os níveis. Para tanto, vale-se da Lei de Diretrizes e Bases da Educação (LDB $)^{9}$, que objetiva regulamentar o sistema educacional no Brasil, tanto na esfera pública, quanto privada em todos os níveis. Tais leis foram criadas e promulgadas para confirmar o que dispõe a Constituição Federal, concernente aos direitos e deveres dos cidadãos, o que inclui o direito de acesso à educação.

\footnotetext{
9 É a legislação que define e regulamenta o sistema educacional brasileiro, seja ele público ou privado. Disponível em: <https://www.significados.com.br/lei-de-diretrizes-e-bases-da-educacao/>. Acesso em: 15 Abr. 2020.
} 
Embora as leis que regulamentam a educação no Brasil tenham avançado, é imperioso considerar que as tecnologias avançaram de maneira muito mais acelerada e, para atender à demanda da sociedade informatizada, isso fez emergir, também, a necessidade de "modelos educacionais" que sejam proativos, maleáveis, cooperativos, colaborativos, personalizados e participativos. Diante disso, novos comportamentos são (re)configurados, exigindo dos envolvidos um maior comprometimento e dinamicidade.

Neste sentido, alguns profissionais da educação se valem da criatividade, inovação e do avanço das tecnologias e adentram no mercado online para sobreviver. Assim, ao utilizar-se dessas tecnologias, disseminam conhecimentos além-fronteiras, ministrando cursos que abrangem, desde áreas específicas, a exemplo de português, história, biologia, idiomas; até cursos livres.

Os aqui intitulados professores nômades digitais ministram suas aulas por meio de plataformas e da recriação de práticas pedagógicas, tornando-as ainda mais criativas e inovadoras. Tal ação, a qual considera a insatisfação com o campo formal da educação, ou mesmo a sobrecarga por ele imposta, ou ainda a grande concorrência para um cargo, fez com que, cada vez mais, os sujeitos criassem táticas de sobrevivência a partir do universo online. Assim:

[...] chamo de táticas a ação calculada que é determinada pela ausência de um próprio [...]. A tática não tem lugar senão a do outro. E por isso deve jogar com o terreno que lhe é imposto tal como o organiza a lei de uma força estranha. Não tem meios para se manter em si mesma, à [sic] distância numa posição recuada, de previsão e de convocação própria: a tática é movimento 'dentro do campo de visão do inimigo', [...] e no espaço por ele controlado. Ela não tem, portanto, a possibilidade de dar a si mesma um projeto global nem de totalizar o adversário num espaço distinto, visível e objetivável. Ela opera, golpe por golpe, lance por lance. Aproveita as 'ocasiões' e delas depende, sem base para estocar benefícios, aumentar a propriedade e prever saídas (CERTEAU, 2009, p. 94-95).

A partir dos conceitos de táticas e estratégias é possível compreender as posições distintas ocupadas pelos indivíduos na sociedade e na relação desses com o cotidiano. Mesmo com a presença e limitações das estratégias dos mais fortes (Estado, empresários etc.), que, de vários modos, exercem poder sobre os mais fracos, eles encontram maneiras de driblá-las, na medida em que criam mecanismos de ação diante do que lhes é imposto. Segundo Certeau (2009, p. 96), “[...] as táticas apontam para uma hábil utilização do tempo, das ocasiões que apresenta e também dos jogos que introduz nas fundações de um poder”. São, portanto, alterações e 


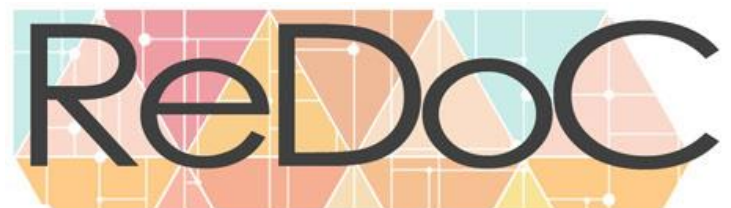

\section{Revista Docência e Cibercultura}

modificações dos mais fracos que criam formas de sobressair perante as limitações impostas pelas estratégias e de seus agentes de fomento.

Neste sentido, é justamente com táticas que os professores nômades adentram no mercado online, para "vender" cursos livres, em diferentes áreas, e para públicos heterogêneos, e, para tanto, favorecem-se dos recursos oferecidos na internet, a exemplo de sites e blogs, como interface de uso profissional. Em contrapartida, sobre a tendência do uso do blog para fins de postagens de conteúdos em áreas específicas, Nascimento (2015, p. 22), afirma que: “A partir do momento em que foi percebida a potencialidade dos blogs para atender a objetivos comerciais, identificou-se, também, que seria possível angariar proventos financeiros como o uso da ferramenta".

Assim, os blogs se configuram como um dos principais requisitos que levaram os professores nômades a desenvolver suas atividades educacionais por meio dele, com o propósito de ampliar os cursos livres para um público ilimitado. De fácil manuseio, os blogs são páginas da web, cujos conteúdos são publicados em ordem cronológica e atualizados por seus usuários com frequência. Pinto (2002, p. 23) afirma que, “[...] em geral, as postagens são apresentadas na ordem inversa à que foram enviadas, ou seja, a primeira postagem da página é geralmente a mais recente (isso pode ser mudado pelo blogueiro)".

Os textos escritos nos blogs são denominados de posts e podem ser de autoria dos seus idealizadores ou de outras pessoas, desde que sejam autorizadas. Além disso, os blogs utilizados pelos professores nômades possuem links que direcionam para outras páginas e também permitem que as pessoas se cadastrem, além de possuírem publicação de imagens, áudios, vídeos, e-book. Por fim, reforça-se que todos os conteúdos são direcionados para algum tipo de aprendizagem, o que reforça a ideia de o blog apresentar-se enquanto um espaço que possibilita diálogos e trocas de informações e materiais.

Os professores nômades, portanto, beneficiam-se continuamente das interfaces dos sites e blogs para disponibilizar seus serviços por meio de publicações e informações que interessam aos seus distintos públicos. Assim, ao analisar os blogs dos professores nômades, foi possível observar que se assemelham nos seguintes aspectos: flexibilidade em desenvolver o trabalho, liberdade, aprendizado, autoconhecimento, fazem sua própria rotina de trabalho, viajam, conhecem pessoas de outras culturas, podem estar em lugares antes inimagináveis dadas as condições financeiras restritivas, melhor qualidade de vida, experimentam novas experiências, saem da zona de conforto e se valem da tecnologia para desenvolver as atividades, ressignificando, assim, o modelo de trabalho tradicional. 


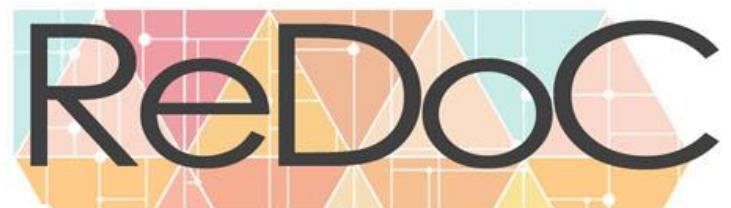

\section{Revista Docência e Cibercultura}

Salienta-se que ainda há uma predominância da forma tradicional de trabalho, porém, com a alteração dos modelos de espaços geográficos, tal realidade tem se modificado, porque, para as profissões que podem ser administradas totalmente online, eclode um número considerável de pessoas que, insatisfeitas ou mesmo sem oportunidade no trabalho tradicional, aderiram ao modelo de trabalho em que o sujeito pode desenvolver suas atividades de forma descentralizada e gerenciando sua rotina como melhor lhe convier.

Para Matos (2016), os modelos de trabalhos mais flexíveis têm sido cada vez mais desenvolvidos em países como: Brasil, China, Cingapura, Austrália, Bélgica e Reino Unido; principalmente nas grandes empresas e por nômades digitais autônomos, entretanto, não se pode negar que tal forma de trabalhar não está carregada, apenas, de um lado bom e prazeroso, pois, como apresenta um campo infinito de possibilidades, os envolvidos precisam estar preparados para as dificuldades que podem surgir, desde situações estruturais, como a fragilidade ou ausência de internet, a desafios humanos, como a busca constante de novos clientes ou o sentimento de frustração, quando as expectativas superam o real.

No caso dos professores nômades brasileiros, esses tiveram, como campo percussor de atração, a modalidade de Educação a Distância, que, segundo Lima (2016), é uma modalidade que se expande, axiomaticamente, com o avanço da tecnologia, permitindo facilidade ao seu acesso, por isso, a partir dela, houve uma procura por cursos que variam entre profissionalizantes e superiores a cursos livres, em razão de fatores como: a não presencialidade, flexibilidade e a utilização de suportes como a tecnologia, a internet e as redes sociais, que proporcionam uma comunicação em tempo real e atendem às necessidades da maioria das pessoas que, de outro modo, não teriam condições de estudar. Tais mudanças fizeram com que alguns professores, aproveitando o espaço financeiramente rentável, automaticamente se lançassem no mercado online para ministrar aulas e cursos livres utilizando as redes sociais para atrair um público.

Neste sentido, para teorizar sobre a prática docente e seu labor em sala de aula, é necessário considerar as diversas multiplicidades de saberes e os espaços utilizados para suas práticas. Vale ressaltar, como afiança Certeau (1994, p. 109), que “[...] as práticas cotidianas estão na dependência de um grande conjunto, difícil de delimitar e que, a título provisório, pode ser designado como os dos procedimentos. São esquemas de operações e manipulações técnicas”. Sendo assim, não é apenas saber, mas, saber como fazer, ou seja, o professor precisa desenvolver sua prática, mas também exercer a função de mediador de culturas e atores diversos, que se encontram no mesmo ambiente, buscando os mesmos objetivos. Assim, são estes atributos que, acrescidos de outros, denotam os modos de atuação dos professores nômades. 
Com os "esquemas de operações", de Certeau (1994), os quais caracterizam o professor nômade, foi possível verificar que esses se pautam em: buscar alternativas para atender às demandas da sociedade informatizada, cujo público é caracterizado por estudantes digitais; desenvolver propostas pedagógicas atualizadas; (re)criar materiais didáticos interativos; ensinar como ser autônomo na realização das tarefas; proporcionar aprendizagens ativas e interativas; criar atividades didáticas apropriadas para as propostas dos cursos, além de propiciar a troca de experiência entre os pares professor/aluno, aluno/aluno.

Nesta lógica, tais professores planejam e realizam suas propostas pedagógicas ancoradas no ideal de mobilidade, cuja metodologia é orientada por objetos de aprendizagens interativos que ficam armazenados num repositório e podem ser acessados pelos alunos, no momento em que lhes for oportuno.

Compreende-se, assim, que os professores caracterizados, enquanto professores nômades digitais, percebem a educação como algo que, desde seu surgimento, foi sistematicamente organizado, porém, na sociedade atual, surgem novos modos de sociabilidade, novos diálogos com a população, novas plataformas, mídias sociais, e, neste sentido, o professor precisa repensar sua prática e reformular os conteúdos, de modo que contemple uma sociedade tecnológica que transita no ciberespaço, conforme destaca Lemos (2002, p. 148), para quem o ciberespaço "[...] é hoje um espaço (relacional) de comunhão, colocando em contato, através do uso de técnicas de comutação eletrônica, pessoas do mundo todo".

Sob tal enfoque, o processo também muda, não que deixe de lado as práticas de outrora, como os impressos, por exemplo; mas toma posse de outros recursos didáticos que diferem daqueles, pois atendem ao seu espaço e tempo.

Neste contexto, é importante compreender que os professores nômades se valem de dois tipos de táticas: a primeira é a divulgação do curso ofertado, por meio de postagens que os convidam a experimentar o serviço oferecido. Para isso, disponibilizam materiais didáticos como: posts, aviso de simulados, quiz, livros digitais, áudios e vídeos, utilizando-se também das redes sociais e dos canais do YouTube para atingir maior número de participantes. Há também a característica de venda de produtos oferecidos, entre eles: cursos, aulas e palestras. Estes encaminhamentos, seguidos pelos nômades, representam os processos que objetivam atrair novos clientes/alunos, ou seja, são as "artes de fazer" e manter-se no negócio.

O segundo tipo de tática está relacionado ao fazer aprender, pois, nos serviços prestados pelos nômades digitais, encontram-se táticas cada vez mais dinâmicas e que objetivam a aprendizagem dos seus alunos. Sobre a escolha e apropriação dos recursos escolhidos, por 


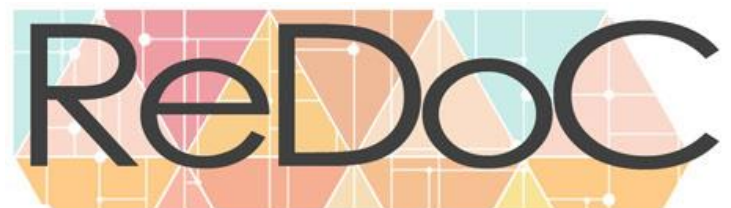

\section{Revista Docência e Cibercultura}

exemplo, cada professor o elege segundo a disciplina ofertada e o público-alvo, ou seja, para quem os cursos são direcionados, representando sua preocupação com a realidade do aluno, garantindo assim não só o interesse, mas a continuidade no curso.

Por exemplo, a professora Lívia Alencar se utiliza de recursos voltados para a técnica de contação de histórias, logo, apropria-se de recursos direcionados para aqueles que atuam com um público infantil. Segundo esta professora, os recursos mais usuais na sua prática são os usos de fantoches e adereços, músicas, mímicas, dinâmicas, expressão corporal e facial, entonação adequada de voz (evitar vícios de linguagens), interação com o público, técnicas de mediação de leituras e atividades lúdicas.

Já os professores Rodolfo Neves e Daniel Pereira, do blog "História online", utilizam recursos, como mapas, playlist sobre conteúdos de história atuais, áudio em MP3, resumos, listas de exercícios, simulados online e vídeos. Por outro lado, o professor Jubilut, do blog "Biologia Total", também se vale de recursos adequados para o seu público-alvo, a exemplo de videoaulas, simulados, posts contextualizados sobre novidades no âmbito da disciplina, análise de provas do Enem e de vestibulares de anos anteriores.

De igual modo, o professor Mairo Vergara, do curso de "Inglês" online, utiliza recursos, a exemplo de livro digital, cujos conteúdos são explicados, também, por meio de videoaulas no Youtube, posts com texto explicativo através de podcast, além de fazer a "convergência" dos conteúdos para as interfaces: fanpage no Facebook, canal no YouTube e no Instagram.

Ao analisar as práticas professorais dos nômades pesquisados, foi possível perceber que elas estão alicerçadas em duas vertentes: a primeira, aquela adquirida na sala de aula convencional, com o uso dos impressos e no modo de organizar os conteúdos sistematizados hierarquicamente; e, no segundo momento, fazendo uso da tecnologia e da internet para atingir a um público por meio de recursos que o envolvem.

Sobre o uso dos recursos audiovisuais, pode-se afirmar que "O aspecto mais espetacular da era digital está no poder dos dígitos para tratar toda informação, som, imagem, vídeo, texto, programas informáticos com a mesma linguagem universal, uma espécie de esperanto das máquinas" (SANTAELLA, 2003, p. 70-71).

No que diz respeito ao método empregado pelos professores nômades, observa-se uma pluralidade deles, visto que há uma dinamicidade nos materiais e na forma de abordagem dos conteúdos, estes diferentes, pois os professores são de áreas distintas, e, por esta razão, o público também difere, porém, as dinâmicas de apresentação dos conteúdos nos blogs seguem 


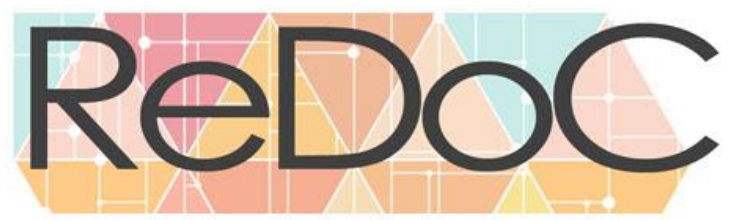

\section{Revista Docência e Cibercultura}

a mesma lógica, ou seja, os conteúdos aparecem tais quais os livros didáticos em ordem sequencial.

Por outro lado, os benefícios comunicacionais direcionados à área pedagógica, ou seja, o fazer aula no espaço virtual, não devem ser ignorados, pois, além de proporcionar maior comodidade para alunos e professores, atingem a um público maior, devido ao fato de, neste espaço, ser o desejo de aprender o motivador e não a obrigação.

Partindo deste pressuposto, observa-se que os professores nômades podem contribuir para uma nova formatação das práticas educativas nas escolas, onde ainda há professores adeptos dos métodos e materiais tradicionais que perpetuam a transmissão e a reprodução do conhecimento, além de se manterem engessados em conteúdos preestabelecidos.

\section{CONVERGÊNCIA VERSUS TRANSMIDIAÇÃO: O MÉTODO PEDAGÓGICO COMPATILHADO EM REDE}

Toda ação educacional é norteada por uma metodologia com a finalidade de atingir os objetivos pretendidos. Partindo deste pressuposto, compreende-se que, no âmbito da educação, um método demanda uma sequência de ações e materiais que o professor traça sistematicamente para alcançar suas metas. Desta forma, trata-se de um procedimento que engloba o processo de ensino.

Segundo Anastasiou e Alves (2009, p. 23), "Cabe ao professor planejar e conduzir esse processo contínuo de ações que possibilitem aos estudantes, inclusive aos que têm maiores dificuldades, ir construindo, agarrando, apreendendo [...], em momentos sequenciais e de complexidade crescente". É, portanto, por meio do método que o professor organiza as informações que o ajudarão a orientar e adequar seus conteúdos de modo que atenda ao seu público-alvo.

Em contrapartida, a escolha de um método tem também, como finalidade, guiar o tempo do professor em relação à organização das atividades a serem desenvolvidas e facilitar o percurso pedagógico do processo educativo. Desse modo, para alcançar seus objetivos, portanto, os professores se valem, neste contexto, de métodos individualizados e/ou socializados, ou seja, tanto pode ter, como foco, a aprendizagem de forma individual, cuja ação do professor está pautada em observar o ritmo de aprendizagem do aluno, ou por meio das atividades 


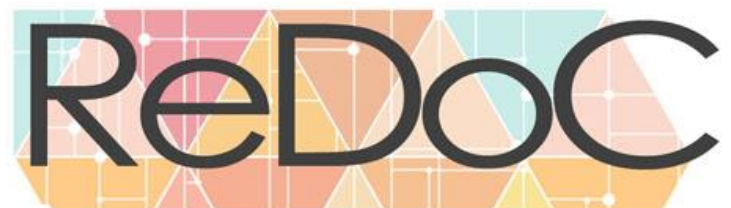

\section{Revista Docência e Cibercultura}

desenvolvidas em grupo, quando oportuniza práticas de interação e aprendizagem coletiva. Ressalta-se que este último tem sido empregado com mais afinco pelos professores, no cotidiano escolar, com a finalidade de proporcionar para os alunos uma aprendizagem embasada na troca de experiências entre os pares, professor/aluno, aluno/aluno.

Neste contexto, encontram-se os professores nômades, os quais se apropriam de métodos diferenciados para atender aos seus alunos, e, assim, tentar garantir novas aprendizagens.

A professora Alencar, por exemplo, ministra cursos que ensinam vários métodos de contação de histórias, além de recursos para enriquecer as histórias, como dinâmicas, músicas, técnicas de interação e mediação de leituras e como inventar histórias. No desenvolvimento de suas práticas, percebe-se a importância do alinhamento entre conteúdo, recursos e ações. Sendo assim, nota-se que a dinâmica dos cursos ofertados por Alencar também segue um método, o qual parte do planejamento, momento em que realiza as escolhas de conteúdo, de recursos e de suas táticas.

Além disso, para ampliar e divulgar seu método de contação, objetivo dos seus serviços, utiliza o blog, o Facebook, um canal no YouTube e o Twitter, fazendo, assim, a "convergência" dos conteúdos, termo cunhado por Jenkins (2009, p. 29) para referir-se "[...] ao fluxo de conteúdos de múltiplas plataformas de mídia, à cooperação entre múltiplos mercados midiáticos e ao comportamento migratório dos públicos dos meios de comunicação".

Diante do exposto, é necessário considerar, sobre a professora Lívia Alencar, que, embora utilize "táticas" diferenciadas para ensinar, sua prática não se configura como uma transmidiação, visto que suas histórias não são (re)contadas com acréscimos dos personagens das narrativas, de modo a completar o enredo. Sobre tal enfoque, Gosciola (2011) afirma que, para ocorrer a transmidiação, é necessário apresentar as etapas:

Partir de uma narrativa inicial; definir claramente as personagens, de primárias a secundárias até figurantes; multiplicar as tramas: desenvolver a vida de cada personagem; distribua as tramas entre as novas mídias; integrar as tramas e os meios de comunicação, tentando a unicidade e coerência do trabalho (GOSCIOLA, 2011, p.7).

A título de ilustração, lança-se mão de um material produzido pela referida professora, e disponibilizado na página do seu blog ${ }^{10}$, a História do "Gato Gigante", que reforça o

\footnotetext{
${ }^{10}$ Disponível em: <https://historiasdalivia.com.br/2017/10/03/historia-infantil-o-gato-e-o-gigante/>. Acesso em: 20 Mar. 2020.
} 


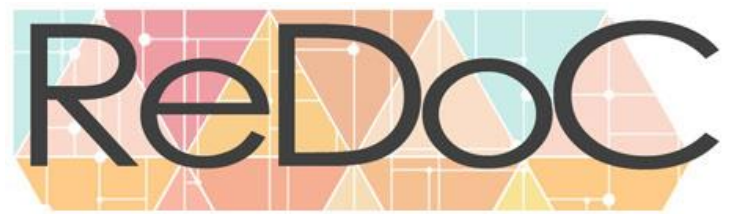

\section{Revista Docência e Cibercultura}

posicionamento de Gosciola (2011) sobre transmidiação. Segundo a nômade, antes de contar uma história, é necessário preparar a plateia.

Ela explicita, também, como uma história pode ser contada para cada faixa etária de idade: “A história de hoje é bem divertida e pode ser usada para trabalhar os opostos (frio e quente, em cima e embaixo, grande e pequeno, etc.) com as crianças" (ALENCAR, 2017, online). Algumas histórias são de autoria da nômade; em outras, faz algumas adaptações ou as recria e são disponibilizadas no seu e-book e nas plataformas as quais utiliza. Em relação às produções que não são de sua autoria, explica:

Eu não sou a autora dessa história. Eu a ouvi há vários anos e não sei quem é o autor dela. Eu a tenho recontado para o meu filho com as minhas próprias palavras e a escrevi abaixo do meu jeito (com um título que eu inventei) e provavelmente fiz mudanças nela também, pois já não me lembro exatamente como era a história original. Como diz o ditado: "Quem conta um conto, aumenta um ponto". Se você souber quem é o autor dessa história, pode me falar nos comentários, por favor (ALENCAR, 2017, online).

A contadora de histórias utiliza as mídias referindo-se aos mesmos assuntos, porém, no caso da fanpage, tem como principal finalidade divulgar seus cursos, ou seja, no menu inferior direito da página, encontra-se a indicação para cadastro, e, no esquerdo, os botões de interação (curtir, seguir e compartilhar) das páginas das redes sociais. Há ainda, no lado direito da página, a opção "enviar mensagem", ou seja, a nômade interage com os supostos "clientes", para tirar dúvidas sobre o curso por meio de trocas de mensagens.

Ao analisar o conteúdo disposto na página do blog e o da fanpage, observa-se que a nômade realiza diferentes ações nas duas plataformas. Acrescenta-se, ainda, que, no canal do YouTube, a ela disponibiliza vídeos em duas modalidades: a primeira, contação de histórias; e a segunda, o curso online, como pode ser entendido por meio da visualização da imagem e da leitura da mensagem: "Faça o meu Curso de Contação de Histórias gratuito e adquira o Certificado de 120 horas no valor promocional pelo link: http://cursopratico.infantilhisto rias..." (ALENCAR, 2017, online). Sobre esta questão, considera-se importante referenciar Jenkins (2009, p. 29), ao afirmar que:

A circulação de conteúdos - por meio de diferentes sistemas de mídias, sistemas administrativos de mídias concorrentes e fronteiras nacionais depende fortemente da participação ativa dos consumidores. Meu argumento aqui será contra a ideia de que a convergência deve ser compreendida principalmente como um processo tecnológico que une múltiplas funções dentro dos mesmos aparelhos. 


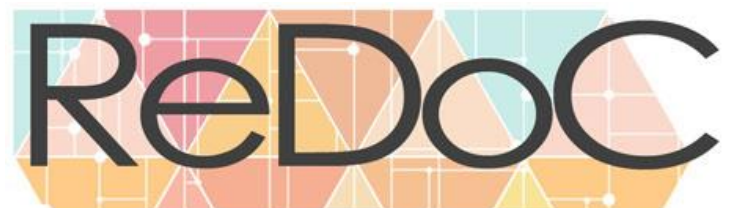

\section{Revista Docência e Cibercultura}

Como se pode perceber, os professores nômades se valem de métodos diferenciados para trabalhar no mercado online a partir de táticas. Neste sentido, (re)inventam novas formas de ensinagem a partir do uso de ambientes virtuais de aprendizagem.

O professor Mairo Vergara, que leciona a disciplina língua inglesa, também faz a divulgação dos seus cursos da seguinte forma: imagens, textos e um link que direciona para outra página, e, inclusive, explica como instalar o Anki no computador ou android, com a finalidade de ouvir a mensagem repetidas vezes. Tal mensagem refere-se ao áudio do conteúdo explicado sobre a pronúncia das palavras.

Outrossim, na fanpage no Facebook, o professor reúne vídeos com dicas de inglês, posts e informações sobre contato e as opções curtir, comentar e compartilhar. Ressalta-se que os mesmos vídeos, dispostos nesta rede social, também estão no canal no YouTube, mas não há novidade em relação às explicações dos conteúdos nem informações complementares que se configurem como narrativas transmídias. O mesmo ocorre com o Instagram, não traz novidades sobre os conteúdos, apenas migram de uma mídia para a outra.

Destarte, a partir da análise dos conteúdos dispostos nas plataformas que os professores nômades se beneficiam para trabalhar, ofertando cursos online para públicos diversificados, foi possível perceber que a forma como os conteúdos são distribuídos nas mídias não se configura como narrativas transmídias, visto que não são acrescentados novos elementos a partir da narrativa principal, ou seja, os alunos acessam os conteúdos nas diferentes mídias, mas não dão novos rumos para as histórias. Corroborando com o que fora explicitado, Gosciola e Versuti (2014) afirmam que as narrativas transmídias podem ser utilizadas como elementos para reproduzir novos conteúdos.

Além disso, na análise comparativa feita entre as narrativas que os professores nômades disponibilizam nas redes sociais, as quais divulgam e vendem seus cursos, ficou explicitado que, embora sejam voltadas para a área da educação, trata-se de adaptações feitas no modo de desenvolver as ações educacionais em ambiente virtual mediado pelo computador, o qual transmite as informações e a comunicação de forma instantânea.

De acordo com Lévy (2002, p. 29), “[...] o computador é uma ferramenta de troca, de produção e de estocagem de informação. A partir do momento em que canaliza e entrelaça uma alta magnitude de fluxo, ele se torna um centro virtual, um instrumento de poder".

Foi apropriando-se desse poder e do domínio da tecnologia e da internet, que os professores nômades descobriram táticas e formas de desenvolver suas atividades a partir do ambiente 


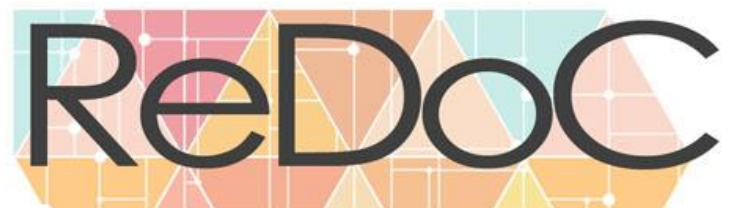

\section{Revista Docência e Cibercultura}

online, de modo a atingir um número indeterminado de público-alvo. A tecnologia e a internet permitem que os sujeitos desenvolvam novos paradigmas que sejam alinhados à sociedade atual, contemporânea, tecnológica e, neste sentido, a educação não poderia ficar isenta do processo.

Partindo deste pressuposto, os professores nômades também (re)configuraram o modo de fazer educação, criando dinâmicas interativas de ensinagem, e, para tanto, utilizam recursos imagéticos, posts, entre outros, para fazer a divulgação dos seus conteúdos nas redes sociais, em conformidade com Jenkins (2009, p. 29), ao afirmar que "[...] refiro-me ao fluxo de conteúdos através de múltiplas plataformas de mídia, à cooperação entre múltiplos mercados midiáticos e ao comportamento migratório dos públicos dos meios de entretenimento que desejam".

Embora a convergência descrita por Jenkins (2009) esteja mais voltada para a área mercadológica, os professores nômades se apropriam, no contexto educacional, para divulgação e propagação de suas propostas metodológicas, que têm sido, de algum modo, positivas, pois há um número considerável de seguidores interessados em adquirir novas habilidades.

Apresentando uma abordagem aproximada, Kenski (2014, p. 209) sinaliza que "[...] conforme o tipo de necessidades, as condições de acesso, os interesses dos participantes, o tempo disponível e a fluência tecnológica, os mesmos recursos podem ser utilizados livremente em cursos mistos [...]".

Assim, considera-se, a partir dos casos analisados, que o tipo de trabalho desenvolvido, as facilidades proporcionadas pelas Tecnologias da Informação e Comunicação (TIC), os recursos disponíveis, os perfis dos nômades, os conteúdos dispostos e as narrativas transmídias podem "[...] estimular a capacidade criativa dos estudantes, bem como a aprendizagem colaborativa e melhor assimilação do conteúdo abordado, podendo ainda construir uma relação interdisciplinar proveitosa" (VERSUTI; GOSCIOLA; SILVA, 2014, p. 52). Então, há que concluir que a narrativa transmídia, mais do que uma potencialidade, pode vir a ser um instrumento importante, neste tipo de empreitada, em que "as artes de fazer" são continuamente reinventadas.

Da mesma forma que a nômade Alencar, os professores nômades, Neves e Pereira, postam informações sobre seus cursos e palestras nas redes sociais da internet. Na página principal do blog, por exemplo, há um enunciado sobre o conteúdo proposto, seguido do link que direciona o aluno para a aula explicativa no canal no YouTube. Tal proposta motiva o aluno a participar 


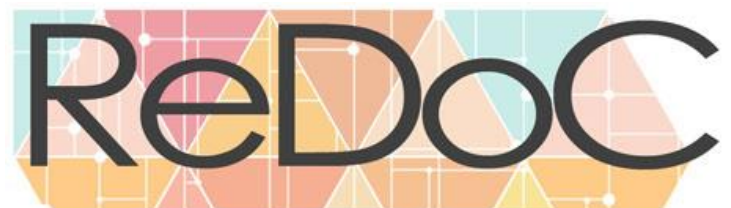

Revista Docência e Cibercultura

da circulação do conteúdo em mídias diferentes, porém, ao clicar no ícone que leva à explanação do professor, observa-se que se trata da explicação detalhada do tema e não uma narrativa transmídia, já que essa se caracteriza a partir do momento em que é percebido que "Os personagens reaparecem em vários meios de comunicação, bem como partes de sua história” (GOSCIOLA, 2011, p. 6).

Na fanpage do Facebook, os professores nômades postam enunciados sobre eventos voltados para as áreas de História, Atualidades, Sociologia e Filosofia, posts contextualizados e fotos. Ao analisar as postagens, verifica-se que são os mesmos conteúdos dispostos nas mídias já descritas, ou seja, não há (re)configuração da história, que é um dos principais requisitos das narrativas transmídias, conforme analogia de Gosciola (2011).

[...] a narrativa transmídia é voltada à articulação entre narrativas complementares e ligada por uma narrativa preponderante, sendo que cada uma das complementares é veiculada pela plataforma que melhor potencializa suas características expressivas, principalmente porque hoje seu público tem comportamento migratório ao decidir qual será a sequência narrativa e por quais plataformas (GOSCIOLA, 2011, p. 8).

Como já mencionado, os professores Neves e Pereira ministram cursos para diversos públicos, com maior destaque para aqueles que vão participar do processo seletivo do Exame Nacional do Ensino Médio (ENEM), e, por essa razão, ao aproximar-se da data da realização do exame, fazem revisão dos conteúdos das provas dos anos anteriores, ao vivo, no canal do YouTube, onde os alunos interagem, tirando suas dúvidas e comentando-os.

Tais conteúdos estão dispostos também no Instagram e Twitter, com inúmeras visualizações por parte de seus seguidores, sem acréscimos de informação, ou seja, a interação dos alunos com o professor é somente para tirar dúvidas, o que vem a ser uma convergência entre as mídias, tendo em vista que, conforme aponta Jenkins (2009, p. 29), "Convergência é uma palavra que consegue definir transformações tecnológicas, culturais e sociais, dependendo de quem está falando e do que imaginam estar falando".

Isso posto, compreende-se, então, que o fazer pedagógico dos professores Neves e Pereira caracteriza-se como uma migração de conteúdos para diversas mídias de maneira atrativa, de modo que seus alunos se sentem motivados para acessar os conteúdos e, de alguma forma, ajuda na divulgação dos cursos quando esses são compartilhados entre os estudantes para outras mídias, corroborando com o que Jenkins (2009) denominou de "cultura participativa". Embora as propostas dos professores sejam a divulgação e propagação do curso, há, no 


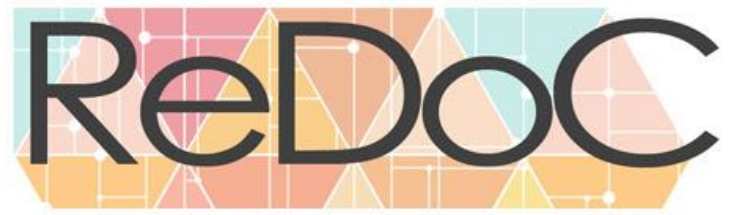

\section{Revista Docência e Cibercultura}

entanto, um cunho educativo nesta dinâmica que possibilita que o trabalho flua e, consequentemente, seja pago.

Ainda na mesma dinâmica dos já citados professores nômades, encontra-se o professor Jubilut, do blog "Biologia Total". Ele também recorre às redes sociais da internet para ministrar seu curso, valendo-se de materiais variados, os quais são distribuídos em várias mídias com o intuito de ensinar seus alunos e, também, divulgar seu trabalho. Ao comparar os conteúdos dispostos nos suportes utilizados pelo nômade, busca-se, também, perceber se há linearidade ou apenas convergência entre as mídias.

Na página do blog são dispostos vários conteúdos, os quais apresentam imagens e textos explicativos, bem como vídeospara reforçar o entendimento dos temas abordados. Já na fanpage no Facebook, o professor divulga os cursos, interage com os alunos por meio de mensagens, bem como possibilita que, ao clicar nos botões (curtir, seguir e compartilhar), os alunos sejam direcionados para outras redes sociais.

O professor Jubilut acrescenta, ainda, fotos, vídeos em destaque de aulas gravadas in loco, sobre determinados assuntos, inclusive em outros países e, por fim, o apelo mercadológico: "O sonho da Universidade pode estar mais perto esse ano... Bora tornar isso real? Vem aí os Extensivos Medicina e ENEM (Ciências da Natureza) [...]”. (JUBILUT, 2017, online). A frase "\#esseanovai!" refere-se a um sorteio que o professor realiza e para participar, basta que os interessados enviem uma foto e a frase, e, assim, aquele que for sorteado ganhará uma semana para estudar no "Biologia Total", sem nenhum custo financeiro.

No canal no YouTube, o nômade disponibiliza uploads ${ }^{11}$, transmissão de aula ao vivo, vídeos em destaque de aulas gravadas, playlists, aulas ministradas por outros professores, comunidades (entrevistas) e dicas de canais por assinatura, bem como as opções para curtir, seguir, compartilhar e enviar mensagem. Assim, no canto inferior direito, há a opção "inscrever-se" para os interessados em fazer os cursos. Diante de tais colocações, observa-se que também não há transmidiação dos conteúdos e sim convergência entre as mídias.

No entanto, no Twitter, os conteúdos de maior relevância são preservados pelo professor, inclusive, a mesma reportagem que é disposta na página do blog também é postada no Twitter, porém, sem nenhum acréscimo explicativo por parte do professor, ou seja, houve

11 Transferir algo do seu computador para a Internet (para outro computador). Disponível em: <http://www.cursosdeinformaticabasica.com.br/qual-a-diferenca-entre-download-e-upload>. Acesso em: 10 Abr. 2020. 


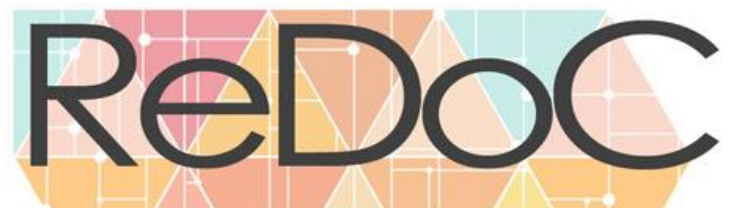

\section{Revista Docência e Cibercultura}

apenas a expansão do conteúdo em diferentes mídias. Neste espaço, anuncia seu produto, o curso que, ao ser curtido e retwitado pelos seus seguidores, aumenta ainda mais a popularidade dos serviços prestados pelo professor nômade.

Além disso, utiliza também a rede social Pinterest para compartilhar imagens e pequenos textos informativos sobre conteúdos de biologia e dicas sobre provas do Enem, sem acréscimos sobre as narrativas. Trata-se, portanto, da circulação dos conteúdos em diferentes mídias. Para Jenkins (2009, p. 29), "[...] no mundo da convergência das mídias, toda história importante é contada, toda marca é vendida e todo consumidor é cortejado por múltiplas plataformas de mídias".

Assim, percebe-se que promover e/ou utilizar-se das várias mídias tem sido de grande importância, tanto na divulgação dos serviços quanto na ampliação de espaços de aprendizagem. Similarmente, o professor nômade Vergara também utiliza métodos, configurados em suas palestras, vídeos, enquetes, podcast, como recursos metodológicos, e faz a convergência por meio das redes sociais e do canal no YouTube, e, para tanto, mostra que há uma relação entre os métodos que são unidos por um mesmo tema e transmitidos por mídias complementares.

\section{CONSIDERAÇÕES FINAIS}

A partir da diversidade dos recursos digitais, do estímulo à autonomia, tanto do aluno, quanto do professor, da flexibilidade dos conteúdos e habilidades, bem como da postura entusiasta dos nômades; é possível "fazer" na sala de aula um novo formato educacional. Assim tem-se evidenciado, mediante as análises feitas nas redes sociais, as quais os professores nômades utilizam para vender seus cursos; as possíveis maneiras de fazer aulas, e que pôde ser concebida também no campo da educação, a partir do uso da tecnologia. Neste caso, criando cursos online e divulgando-os através das redes sociais.

Nesse prisma, ainda é possível compreender como se processam e propagam as informações no ambiente online e quais os obstáculos encontrados neste percurso; também se percebe que trabalhar utilizando a tecnologia não garante que a aprendizagem aconteça, pois é preciso que o professor saiba alinhar os conteúdos de modo que o aluno perceba que uma mídia não substitui a outra.

No itinerário deste estudo, chegou-se ao entendimento de que, com a evolução da internet e da potencialidade das redes sociais, que permitem que os sujeitos interajam e compartilhem 


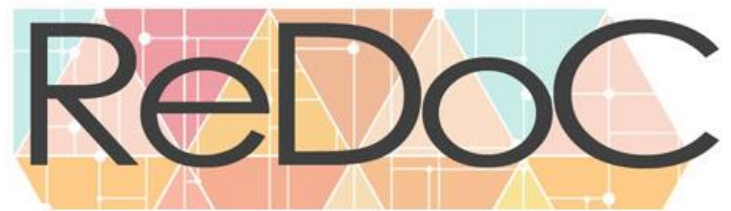

\section{Revista Docência e Cibercultura}

conteúdos, sobretudo, da educação; os professores podem ensinar e, ao mesmo tempo, aprender, visto que a cultura digital permite estar na rede, e a troca de informação ocorre de forma instantânea. Dessa forma, os professores nômades, sujeitos desta pesquisa, (re)inventaram outras configurações para reproduzir e divulgar seus conteúdos em espaços de aprendizagens online.

O estudo mostrou também que o fato de os professores nômades criarem um canal no Youtube, um blog, uma fanpage no Faceboock, entre outras redes sociais, não assegura que este "novo" modelo de ensino dará certo. É preciso também investir na divulgação dos conteúdos propostos para atingir o público-alvo, isto porque a geração atual, tecnológica, é diferente das anteriores, sabe manusear os dispositivos digitais móveis e, a todo momento, troca informações. Assim, cabe aos professores "lincar" suas práticas para não ficar à deriva.

Foi a partir desse universo de socialização em/na rede, que a educação também adentrou nesse universo, e os professores nômades ampliaram seu repertório e se apropriaram de táticas para fazer educação no universo digital.

Por fim, considera-se que em relação, ao fazer educação no mundo digital, o que vem ocorrendo, é uma convergência entre as mídias, mas com potencial para as transmidiações, incorporando as manifestações e as interações à troca que os sujeitos realizam durante o processo de ensino e aprendizagem, que podem, portanto, tornar-se um percurso metodológico válido, uma vez que potencializa as ações pedagógicas e, consequentemente, produz novas aprendizagens, tendo em vista a participação ativa daqueles que se envolvem neste processo.

\section{REFERÊNCIAS}

ALENCAR, Lívia. Questionamentos [mensagem pessoal]. Mensagem recebida por <rozevaniavcesar@hotmail.com> em 5 de mar. 2018.

ANASTASIOU. Léa das Graças Camargos; ALVES. Leonor Pessate. (Org.). Processos de ensinagem na universidade: pressupostos para as estratégias de trabalho em aula. 5. ed. Joinville, 2009.

BRASIL. Lei de Diretrizes e Bases da Educação Nacional. Lei número 9394, 20 de dezembro de 1996. 


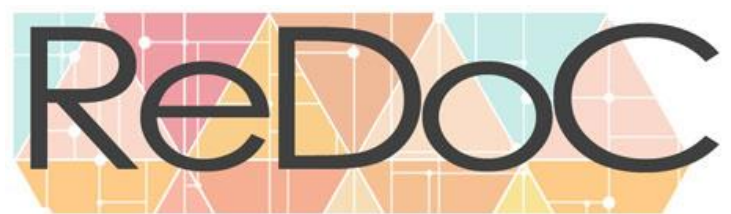

\section{Revista Docência e Cibercultura}

CERTEAU, Michel de. A invenção do cotidiano. 16. ed. Tradução de Ephraim Ferreira Alves. - Petrópolis, RJ: Vozes, 2009.

CERTEAU, Michel de. A invenção do cotidiano. 3. ed. Petrópolis: Editora Vozes, 1998.

CERTEAU, Michel. A invenção do cotidiano: artes de fazer. Petrópolis: Vozes, 1994.

GOSCIOLA, Vicente. Narrativa transmídia: conceituação e origens. In: CAMPALANS, C.; RENÓ, D.; GOSCIOLA, V. (Org). Narrativas transmídia: entre teorias y prácticas. Bogotá: Universidaddel Rosário, 2012, p. 7-14.

GOSCIOLA, Vicente; VERSUTI, Andrea Cristina. Narrativas transmídias e sua potencialidade na educação aberta. In: OKADA, A. (Ed.) Open Educacional Resources and Social Networks: Co-Learning and Profissional Development. London Scholio Research \& Publishung. 2012.

GOSCIOLA, Vicente. Narrativa transmídia: a presença de sistemas de narrativas integradas e complementares na comunicação e na educação. Quaestio: Revista de Estudos de Educação, v. 13, p. 117-126, 2011.

JENKINS, Henry. Cultura da convergência; tradução Susana L. de Alexandria. 2. ed. São Paulo: Aleph, 2009.

JUBILUT, Paulo. Quem é o professor Paulo Jubilut e o Biologia Total? S/d. Disponível em: <https://www.biologiatotal.com.br/sobre.html>. Acesso em 20dez. 2019.

KENSKI, Vani Moreira et al. Educação e comunicação: interconexões e convergências. Educação \& Sociedade, v. 29, n. 104, p. 647-665, 2008.

KENSKI, Vani Moreira. Tecnologias e tempo docente. Campinas: Papirus, 2014.

KOZINETS, Robert V. Netnografia: a arma secreta dos profissionais de marketing: como o conhecimento das mídias sociais gera inovação. 2010. Disponível em: http://bravdesign.com. br/wp-content/uploads/2012/07/netnografia_portugues.pdf. Acesso em: 28 Mar. 2020.

LEMOS, André. Cibercultura, tecnologia e vida social na cultura. Porto Alegre: Sulina, 2002.

LIMA, Daniella de Jesus; MERCADO, Luis Paulo Leopoldo; VERSUTI, Andrea Cristina. A transmídia e sua potência na prática de leitura e produção textual. Revista IberoAmericana de Estudos em Educação, v. 12, p. 1313-1330, 2017.

LIMA, Emerson dos Santos. Educação a Distância no Instituto Federal de Sergipe: um estudo de caso a partir de reflexões dos alunos concluintes do Curso Técnico em 


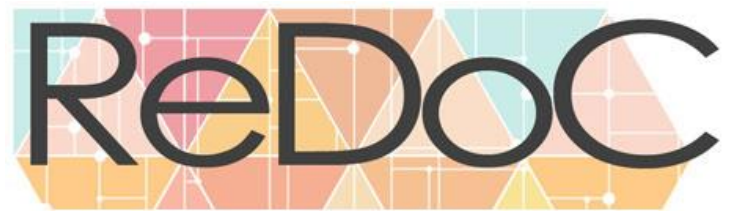

Revista Docência e Cibercultura

Administração. Dissertação de Mestrado, Unit, 2016. Disponível em:<https://tinyurl.com/y96 hv2j7>Acesso em: 25 Abr. 2020.

MATOS, Renata Santos da Frota. Nômades digitais: perfis, motivações. 2016. 65f. Dissertação (Mestrado em Gestão Empresarial) - Escola Brasileira de Administração Pública e de Empresas, Centro de Formação Acadêmica e Pesquisa, Rio de Janeiro.

NASCIMENTO, Naiara. Oss-Emer do. Nomadismo digital e comunicação na web 2.0: uma análise do blog Nômades Digitais. Porto Alegre, 2015.

PINTO, Marcos José. Blogs! Seja um editor na era digital. São Paulo: Érica, 2002.

RENÓ, Denis P; VERSUTI, Andrea Cristina; RENÓ, Luciana T. L. Transmediação e conectivismo: Contemporaneidade para a educação. In: LINHARES, Ronaldo Nunes; LUCENA, Simone; VERSUTI, Andrea. (Org.). As redes sociais e seu impacto na cultura e na educação do século XXI. 1. ed. Fortaleza: Edições UFC, 2012, v. 1, p. 55-83.

SANTAELLA, Lucia. Culturas e artes do pós-humano: da cultura das mídias à cibercultura. 2. ed. São Paulo: Paulus, 2003.

VERSUTI, Andrea Cristina; GOSCIOLA, Vicente; SILVA, Daniel Davi Alves da. Narrativa Transmídia da participação à Educação. In: VERSUTI, Andrea; BERALDO, Rossana; GOSCIOLA, Vicente. (Org.). Formação de Professores: transmídia, conhecimento e criatividade. 1. ed. Recife: EDUFPE, 2014, v. 2, p. 35-52.

Este é um artigo de acesso aberto distribuído sob os termos da Licença CreativeCommons Atribuição Não Comercial-Compartilha Igual (CC BYNC- 4.0), que permite uso, distribuição e reprodução para fins não comerciais, com a citação dos autores e da fonte original e sob a mesma licença. 